\title{
New approach to ensure safety-first culture
}

B arb Farlow wishes she had asked more questions about her daughter Annie's care. Born with the chromosome disorder Trisomy 13, Annie was only a few months old when she died in hospital of what her parents believe may have been a treatable respiratory condition. Months after Annie's death, they learned that a doctor had placed a "do not resuscitate" order on her chart without their consent, and that their daughter had received an undisclosed dose of narcotics that may have caused her rapid, unexplained decline.

"If only I hadn't assumed that we were all on the same page, I could have asked what would happen if this or that occurred, and that may have made a difference," says Farlow, a member of the advocacy group Patients for Patient Safety Canada. "For many of us, it's not until we've experienced harm or a near miss that our eyes are opened to the questions we should be asking."

The Canadian Patient Safety Institute (CPSI) is expanding its work to equip the public, care providers and health leaders to tackle such questions before harm occurs. The nonprofit organization recently launched Shift to Safety, a database of tips and tools for creating a safety-first culture in health care. The initiative will also include webinars, a public awareness campaign and coaching on how to measure safety.

It's a change in tack for CPSI, which previously focused on clinical tools for frontline health workers, says CEO Chris Power. "If you don't also focus on teamwork, communication and culture change, then it's hard to sustain improvements."

The new initiative emphasizes these missing ingredients, she says.

She and others hope the organization will also take advantage of its distance from the health system to rock the boat a little; for example, by providing support for patient activism.

Training is needed to give activists "the savvy to nudge institutions to accelerate the shift towards a culture of safety," says Malcolm Maclure, academic chair in patient safety at the University of British Columbia.

He quotes Dr. Donald Berwick, former adminis-

For health care providers and leaders, for example, CPSI will deliver teamwork training developed by the United States Department of Defense and work with behaviour-change scientists at the Ottawa Hospital Research Institute to provide other resources for influencing culture.

For patients, there are lists of questions to ask during health care visits, as well as links to social network groups and Choosing Wisely Canada, a campaign that supports conversations about unnecessary tests and treatments.

Power says these are the kinds of supports she needed both as a patient with breast cancer and when she led Nova Scotia's Capital Health authority through scandal over a mastectomy mix-up in 2013. She navigated both those storms "by trial and error, but now we have the resources in a one-stop shop."

Farlow notes that the people most affected by safety issues are often reluctant to address them. Health workers want to avoid unnecessary worry and patients are too overwhelmed or don't want to seem rude by questioning care. CPSI is in a good position to normalize the conversation, Farlow says. "There's just something about a national body giving directions, advice and support that seems to speak." trator of the US Centers for Medicare and Medicaid Services: "The biggest lever I have yet seen myself for getting the attention of boards and executives is the voice of patients."

Maclure also cautions against overreliance on tools. "The most famous tool in patient safety is the safe surgical checklist. Does it work? Yes and no. In a randomized trial, it had a bigger impact than many drugs. But when implemented throughout Ontario, there was no detectable impact on severe outcomes initially. Why? Tools are necessary but not sufficient to shift culture."

It's been more than a decade since CMAJ published a study showing that 1 in 13 hospital patients suffers harm during care. Mixed results from the patient safety interventions that followed suggest that success is largely dependent on environment.

Power acknowledges that it was a mistake to think that clinical tools alone could be a "silver bullet."

She says the new Shift for Safety initiative will expand beyond online resources and include efforts to empower patients who may be a lone voice on health care boards or committees. "Those are things we'll continue to work on." - Lauren Vogel, CMAJ

CMAJ 2016. DOI:10.1503/cmaj.109-5310 